\title{
EL ESPACIO NACIONAL Y LAS FRONTERAS COMO VARIABLES DE LAS RELACIONES INTERNACIONALES Y DE LA POLÍTICA EXTERIOR: LA ESPECIFICIDAD DE LAS NEGOCIACIONES TERRITORIALES
}

\author{
NATIONAL SPACE AND BORDERS AS VARIABLES OF INTERNATIONAL \\ RELATIONS AND FOREIGN POLICY: THE SPECIFICITY OF TERRITORIAL \\ NEGOTIATIONS
}

Manuel Rodríguez Cuadros *

\section{RESUMEN}

La territorialidad es una variable esencial de las relaciones internacionales y de la política exterior. El territorio, incluida su proyección marítima, condicionan e influencian las relaciones entre los Estados. Las relaciones de poder, estratégicas, políticas, económico-comerciales y todo tipo de interacción internacional están referidas directa o indirectamente al espacio nacional de los Estados. En esa perspectiva, las dinámicas de la cooperación y conflicto tienen en el territorio y sus expresiones materiales y jurídicas, como la soberanía, los límites, las fronteras, sus áreas de acción más vinculadas a los intereses nacionales, la conciencia y la identidad nacional. Su importancia en acción internacional les confiere regulaciones constitucionales que limitan y regulan las decisiones de política exterior referidas a estos intereses nacionales permanentes. El conflicto es una dinámica privilegiada de la territorialidad. Especialmente en su vinculación con los límites y los factores que definen la identidad nacional. El autor analiza toda esta problemática y la vincula con tipos de conflicto interestatales y los diversos mecanismos de solución de controversias no jurisdiccionales, con un énfasis en la descripción analítica de las especificidades de la negociación territorial.

Palabras clave: Territorialidad, identidad nacional, determinación de fronteras, soberanía nacional, política exterior, mecanismos de solución pacífica de controversias, negociaciones territoriales.

\footnotetext{
* Jurista, diplomático, escritor, embajador en el Servicio Diplomático Peruano. Ministro de Relaciones Exteriores (2003-2005). Ha presidido las comisiones de Derechos Humanos y Desarme de las Naciones Unidas. Abogado de Estado en el juicio en la Corte Internacional de Justicia sobre la delimitación marítima entre el Perú y Chile. Autor y negociador de la iniciativa de la Carta Democrática Interamericana. Ha ejercido también los cargos de Presidente del Comité del Patrimonio Cultural Inmaterial, Presidente del Comité del Patrimonio Mundial y Vicepresidente de la Asamblea General de la UNESCO. Ha sido embajador del Perú en la OEA, las Naciones Unidas en Ginebra, Bolivia y en la embajada del Perú ante la UNESCO. Doctor Honoris Causa por numerosas universidades nacionales y extranjeras. Autor de numerosas publicaciones, entre ellas, "El Perú en el Sistema Internacional del Patrimonio Cultural y Natural de la Humanidad", 2019; "Derecho Internacional de la Delimitación Marítima", 2012; "Delimitación Marítima con Equidad: El caso de Perú y Chile", 2007, "La Soberanía Marítima del Perú: La controversia entre Perú y Chile", 2010; "Maritime delimitation with equity. The case of Peru vs Chile", 2011; "La Política Internacional en el Itinerario Intelectual de César Vallejo" UNESCO, 2018.
} 


\begin{abstract}
Territoriality is an essential variable in international relations and foreign policy. The territory, including its maritime projection, conditions and influences the relations between the States. The power, strategic, political, economic-commercial relations and all kinds of international interaction are directly or indirectly related to the national space of the States. In this perspective, the dynamics of cooperation and conflict have in the territory and its material and legal expressions, such as sovereignty, limits, borders, its areas of action more linked to national interests, consciousness and national identity. Their importance in international action gives them constitutional regulations that limit and regulate foreign policy decisions regarding these permanent national interests. Conflict is a privileged dynamic of territoriality. Especially in its connection with the limits and factors that define national identity. The author analyzes all this problem and links it to types of interstate conflict and the various non-jurisdictional dispute settlement mechanisms, with an emphasis on the analytical description of the specificities of territorial negotiation.
\end{abstract}

Keywords: Territoriality, national identity, determination of borders, national sovereignty, foreign policy, mechanisms for the peaceful resolution of disputes, territorial negotiations.

\title{
El territorio y la identidad nacional como constantes históricas en el contexto de la globalización
}

La relación existente entre la política exterior y las variables del espacio nacional se deriva de la propia naturaleza jurídica y material de las sociedades políticas y del Estado, como un tipo de organización social que supone necesariamente una base territorial.

En las sociedades primitivas esta interacción tuvo su génesis en la consolidación de la vida social sedentaria que vinculó de manera permanente las comunidades políticas con el espacio territorial. Un primer componente de dicha relación es esencialmente propio del ámbito de la política interna y tiene que ver con los recursos naturales y las capacidades de la actividad económica para satisfacer las necesidades de la población.

Desde esta perspectiva, es decir la potencialidad del territorio en materia de recursos para la satisfacción de necesidades, las sociedades políticas de la antigüedad y los Estados modernos acumulan mayor o menor poder en función de la potencialidad económica de su territorio. La dimensión de ese poder varía a través del tiempo básicamente por acción del impacto que sobre los recursos naturales y el significado estratégico o económico de la posición geográfica tiene el proceso de innovación tecnológica.

Otro componente de la relación sociedad política - espacio territorial está constituido por una pluralidad de factores que se derivan de las interacciones entre las sociedades políticas o los Estados, principalmente los intercambios de bienes y servicios, la guerra y el uso de la fuerza como método de soluciones de controversias o de incremento del poder, la negociación como instrumento de la solución pacífica de los conflictos y finalmente el "valor estratégico" del espacio en función de valores económicos, políticos o estratégicos y de la utilidad que se deriva de su posición, sea para la guerra o para la actividad económica. 
Están también las representaciones ideológicas y las conductas sociales vinculadas al sentimiento de pertenencia y de seguridad que la posesión del espacio genera en la población. Incluyendo la valoración cultural que una población hace de su territorio como un factor de identidad, que vincula colectivamente a toda la población en torno a un espacio compartido. En el mundo contemporáneo este sentimiento de pertenencia es inherente a la idea de nación, da origen a la conciencia nacional, constituye la base referencial de los "intereses nacionales" y es el punto de partida del "nacionalismo" o de la "reivindicación nacional".

Estas variables propias de las interrelaciones entre el territorio y la política, con distinta naturaleza, énfasis y significado, han interactuado a lo largo de la historia en las relaciones entre sociedades políticas. Tanto en los sistemas particulares de relaciones internacionales de la antigüedad (el Imperio universal chino y las demás civilizaciones del extremo oriente, la sociedad internacional andina en el Antiguo Perú o los reinos que habitaron el subcontinente mesoamericano) como en la Edad Media o las épocas modernas y contemporáneas de desarrollo del Estado nación. En las sociedades nómadas la territorialidad no fue una carencia absoluta de los grupos y sociedades no tribales (Kratochwil, 1985).

Por estas razones, es decir por la importancia de la territorialidad en la formación de las comunidades políticas autónomas y especialmente del Estado nación contemporáneo, la teoría de las relaciones internacionales, consideradas como ciencia social, asigna al espacio un lugar sustantivo dentro de las categorías de análisis básicas de la política internacional. Y ello porque la territorialidad como base material de los Estados o como referente funcional de los actores no estatales del sistema internacional constituye una constante histórica.

Las interacciones entre los Estados, de estos con los actores no estatales (empresas, organizaciones no gubernamentales, entidades intergubernamentales, grupos y movimientos sociales, políticos, culturales, etc.) y entre los actores no estatales tienen siempre un referente territorial, y dentro de este la noción de fronteras está presente en los múltiples hechos internacionales que conforman las dinámicas de la cooperación y el conflicto. Está presente en la guerra en Bosnia Herzegovina, en las negociaciones de paz entre Israel y Siria, en los acuerdos de libre comercio e integración económica, que unen los espacios territoriales económicamente sin modificar la territorialidad de cada Estado, en la solicitud de visas de un ciudadano particular, o en las barreras migratorias a los flujos humanos interestatales.

En este sentido, el estudio de la función del territorio en las relaciones internacionales no puede constreñirse a la visión jurídica clásica que hace hincapié exclusivamente en aspectos como las competencias del Estado sobre su territorio, los dominios territoriales, los modos originarios y derivados de adquisición de territorios o las consecuencias de la guerra en el ámbito de la territorialidad. Todas estas categorías de análisis jurídico son indispensables, pero el territorio y las fronteras tienen una significación mayor que compete a la sociología, la geografía, la economía y especialmente a la esfera de la ciencia social de las relaciones internacionales.

Por esta razón es indispensable un enfoque multidisciplinario del estudio de la territorialidad en las relaciones internacionales, especialmente en una época como la actual en la que se vienen produciendo enormes mutaciones sociales, políticas, económicas y estratégicas que marcan el tránsito de un sistema internacional recientemente disuelto (el sistema heterogéneo bipolar flexible de la fase final de la guerra fría) hacia uno nuevo, el actual, cuyos contornos definidos 
aún no es posible precisar, aunque se perfila en términos de constituir un sistema homogéneo unipolar flexible.

Los nuevos desafíos de la función que toca desempeñar a los espacios en la política mundial contemporánea se expresan contradictoriamente entre las tendencias opuestas de la superación de la territorialidad por parte de los mercados y el incremento de las barreras fronterizas en términos sociopolíticos, (aun muros físicos como el que se construye en la frontera estadounidense mexicana), por ejemplo el libre flujo de las migraciones. Se expresa también en el mundo de las ideas, en el languidecer o el debilitamiento de las grandes ideologías políticas de carácter universalista que no reconocen fronteras, y el consiguiente surgimiento o resurgimiento de ideologías nacionales, regionales o culturales referidas casi siempre a valores compartidos solo en estrechas fronteras nacionales o regionales; en la dinámica opuesta de la revolución de las comunicaciones que hace de todos los territorios del mundo un solo espacio para la palabra, la voz o la imagen, y las corrientes xenófobas, racistas y excluyentes del neo conservadurismo europeo y norteamericano.

En fin, en la existencia -por primera vez en la historia- de una sociedad internacional ampliamente organizada con criterios y algunas pautas y mecanismos de gobernanza mundial, y el surgimiento de múltiples conflictos en los que las variables del territorio, el espacio nacional y la frontera siguen movilizando pueblos en defensa de su identidad y patrimonio.

Estos hechos y tendencias requieren un nuevo examen de la territorialidad como variable política en las relaciones internacionales contemporáneas. Pero más allá de esta tarea difícil y compleja, la experiencia histórica y la realidad de la conducta de pueblos y gobiernos muestran que se pueden extraer algunas tendencias definidas:

La revolución tecnológica actual y su impacto en la creación progresiva de una economía globalizada no significa más que eso. Es decir, la paulatina aunque segura relocalización de los procesos económicos, de la producción, distribución y consumo de bienes y servicios a escala mundial, incluyendo la utilización del capital y la mano de obra en esa misma escala planetaria, en función de criterios de competitividad y costos.

Este proceso no implica un cambio dramático en la estructura básica de las relaciones internacionales que son sustantivamente interestatales. Los Estados y el parámetro territorial constituyen los referentes de la liberalización o regulación del mercado internacional y las actividades económicas de las empresas, incluidas las empresas transnacionales, finalmente siempre tienen una base nacional. Por ser transnacional la General Motors o la IBM no dejan de ser empresas norteamericanas que forman parte de una economía nacional y que operan en los mercados de otras economías nacionales.

De lo anterior se deriva algo que es obvio para las potencias, para los países de una dimensión mediana y para aquellos en desarrollo que poseen una base de sustentación nacional consolidada. Independientemente del grado de apertura a las cadenas globales de valor: insertarse en el proceso global maximizando sus beneficios y minimizando o eliminando aquellos aspectos que afectan a sus intereses. Este proceso de inserción en la economía global no es excluyente con la afirmación de la base nacional del Estado y la sociedad. Por el contrario, insertarse eficazmente en la globalización requiere permanencia y consistencia de las políticas económicas nacionales, seguridad jurídica interna y paz social, la no existencia de 
grandes brechas de pobreza e injusticia social, así como la generación amplia de consensos nacionales.

Requiere también un Estado moderno, ágil, con cuadros capacitados, no corrupto y con servicios especializados para su administración y gestión. Exige la existencia y ejecución eficiente de planes a largo plazo, coherentes, de aplicación sistemática, que compatibilicen los requerimientos del crecimiento y la expansión económica, la seguridad nacional y la política exterior.

Los problemas, aspiraciones e intereses de los Estados vinculados a cuestiones inherentes a su estructura nacional, como las cuestiones de la territorialidad, las fronteras y los límites, o los concernientes a sus relaciones políticas de cooperación o conflicto con vecinos y otros actores internacionales, no solo no desaparecen con la globalización, sino que adquieren nuevos y complejos desafíos. Por esa razón, el debate electoral norteamericano se centra sobre los intereses de la nación en el frente interno y especialmente en materia de política exterior, por esa misma causa en Europa Oriental, luego de la guerra fría, se desarrolló un proceso de redefinición de las bases nacionales y territoriales de los Estados. La guerra de Bosnia fue una guerra por espacios territoriales en función de etnias y nacionalidades. Por esa misma motivación el futuro de la paz en el Medio Oriente depende de un territorio nacional para la Entidad Autónoma Palestina, de la reintegración territorial del espacio nacional sirio o de la necesidad de Israel de contar con fronteras definidas y seguras con todos sus vecinos.

Por estas mismas razones, el Perú, en momentos en que pugnaba por definir su inserción en la economía global, tuvo que enfrentar entre enero y marzo de 1995 una guerra con el Ecuador. Estas realidades del mundo actual, que son menos simples que las auroras de la apariencia transnacional, significan que las variables del territorio, los límites y las fronteras son factores permanentes de la política internacional y por ende de la política exterior del Perú.

Desde una perspectiva analítica, las variables territorios y fronteras son simultáneamente factores de cooperación (integración, acuerdos de libre tránsito fronterizo, etc.) y de conflicto (tensiones militares, incidentes fronterizos y guerras de origen territorial). En muchos casos la cooperación y el conflicto se presentan de manera simultánea interactuando dinámicamente en torno a un solo proceso internacional.

Por otro lado, ambas variables inciden en la política internacional de manera diferenciada según actúen a nivel del sistema internacional o determinados subsistemas (función del territorio y las fronteras en las macro relaciones internacionales) o en la política exterior de un país determinado (función del territorio y las fronteras en las micro relaciones internacionales). En la perspectiva de un análisis sistémico, el estudio de las variables del territorio y las fronteras en una dimensión micro (la política exterior del Perú) debe tener en cuenta los impactos del sistema internacional y del subsistema interamericano, dimensión macro, en el desarrollo de las negociaciones y conflictos que han configurado la actual fisonomía espacial del Estado peruano. 


\section{El espacio territorial y la determinación de las fronteras en la política exterior de los Estados}

El estudio de la política exterior de los Estados corresponde a las micro relaciones internacionales y debe también orientarse por un enfoque de teoría política con insumos multidisciplinarios. Se entiende por política exterior las acciones que realiza un Estado para obtener determinados objetivos -previamente diseñados- en sus relaciones con los otros Estados y con las organizaciones multilaterales del sistema internacional. La política exterior además de objetivos y acciones requiere medios de acción y recursos.

Toda política exterior pretende maximizar los impactos positivos de las relaciones con otros Estados o con el sistema internacional, y al mismo tiempo reducir o eliminar los impactos negativos.

Aludiendo a esta connotación, Marcel Merle, define la política exterior como la parte de la actividad estatal que se orienta hacia afuera, es decir que trata, por oposición a la política interna, de los problemas que se presentan más allá de las fronteras (Merle, 1984).

Un problema esencial que plantea la teoría de las micro relaciones internacionales es la relación que existe entre la política exterior y la política interna. Existe al respecto una abundante literatura especializada que marca distintas aproximaciones y valoraciones.

Del debate teórico se derivan tres interrogantes esenciales: ¿la política interior y la política exterior son órdenes del pensamiento y la realidad autónomos?; si por el contrario están interrelacionados ¿la política interior tiende a determinar o influenciar a la política exterior o a la inversa?; y, finalmente, ¿es posible aislar e identificar los criterios de análisis que permitan explicar las interrelaciones entre la política interna y la política exterior?

Las respuestas a estas interrogantes están aún en discusión. Sin embargo, es evidente que considerar a la política exterior de manera independiente de la política interna es un anacronismo conceptual y teórico. Son órdenes estrictamente interrelacionados, más aun se trata en realidad de dos dimensiones de la vida política. Una, la interna, tiene lugar al interior de los Estados, donde el poder estatal es un centro de imputación de deberes y derechos, es centralizada y quien detenta el poder ejerce legítimamente la autoridad y aplica coercitivamente la ley. La otra, la política internacional, se ejerce en una sociedad descentralizada donde no existe un Estado único, sino una pluralidad de entes estatales, con igualdad soberana, donde ninguno puede ejercer legítimamente el poder sobre los demás. En ese contexto la política interna y externa se implican mutuamente.

No se trata de interacciones mecánicas ni predeterminadas, y no es posible señalar a priori la determinación de la política interna sobre la externa y viceversa, pues ello depende de las circunstancias históricas, de la materia de los problemas, de los actores en juego, de las características de los regímenes de gobierno y de una serie de factores contingentes. Todos ellos susceptibles de identificar y aislar para el análisis situacional y dar previsibilidad a las decisiones que se adopten a partir del diagnóstico.

La invocación de factores propios de la política interna y la política externa para justificar, alentar o inhibir determinadas decisiones o cursos de acción, forma parte también de las decisiones que adoptan los gobiernos. 
Es usual recurrir a los problemas, desafíos y presiones externas para resolver problemas internos y, contrario sensu, remitirse a los problemas de la política interna para justificar determinadas acciones de política exterior. En todo caso, esta doble vía de utilización de "lo externo" y "lo interno" no hace sino confirmar las mutuas interrelaciones y auto implicancias de estos dos órdenes de la actividad política.

Las interacciones entre la política interna y la política exterior tienden a intensificarse cuando se trata de cuestiones vinculadas al territorio, las fronteras o la identidad nacional.

Con relación a la variable territorio, esto se expresa en el régimen constitucional que tienen todos los Estados respecto a su territorio. En los ordenamientos constitucionales, por regla general, se regulan las cuestiones relativas a la soberanía terrestre, aérea y marítima en relación con el territorio y el espacio nacional, sobre las negociaciones territoriales con otros Estados, regímenes de intangibilidad del territorio o normas que condicionan su cesión, venta o permuta, así como sobre la negociación de los tratados de límites y los regímenes fronterizos (política exterior) que usualmente están supeditados a aprobación por parte del órgano legislativo (política interna). Esta esfera de las relaciones entre la política interna y la externa en torno a la territorialidad y los asuntos de fronteras, de neto carácter jurídico, se complementa con las previsiones de la defensa nacional que por su propia naturaleza están referidas al territorio, las fronteras y la soberanía aérea y marítima.

En la mayoría de los regímenes de gobierno la política exterior es un asunto propio y de responsabilidad del ejecutivo. Sujeto a un relativo y limitado control del legislativo, que justamente se refiere sustantivamente a las cuestiones territoriales y de fronteras que tienen relación con el ejercicio de la soberanía nacional, la defensa, las declaraciones de guerra y las negociaciones de paz.

No existe una esfera de las actividades del legislativo en las que usualmente esté más facultado para ejercer un control de la política exterior desarrollada por el ejecutivo, que la referida a las cuestiones territoriales y fronterizas con connotación en el ejercicio de la soberanía nacional. En muchos casos, por ejemplo, determinadas decisiones de política exterior que atañen a la territorialidad son sometidas a plebiscito, como los ocurridos en Noruega, Dinamarca y Suecia para integrarse o no a la Unión Europea. En otros casos se han pactado plebiscitos para la autodeterminación nacional, que es una opción también territorial (Namibia, Islas Comores, Sahara Español y el Quebec). En otros, se han pactado plebiscitos para determinar la pertenencia de ciertos territorios o poblaciones a uno u otro país como consecuencia de guerras y ocupaciones militares (el plebiscito contemplado en el Tratado Peruano Chileno de 1883).

Tanto en las democracias desarrolladas como en las del mundo en desarrollo, la participación de los partidos políticos, de las fuerzas sociales y económicas y de los medios de comunicación en los asuntos de política exterior es creciente, aunque su influencia real en el proceso de toma de decisiones sea muy desigual o limitada (quizá con la excepción de los medios de comunicación por su condición de ser vehículos de formación de opinión pública). Así por ejemplo, es escasa la influencia de estos actores no estatales internos en una negociación sobre el terrorismo internacional o sobre una reducción arancelaria de los granos de café. Aunque por razones de la existencia de una mayor articulación entre la sociedad civil y el Estado, en los países industrializados siempre existe una tendencia a que la política exterior no tenga una 
autonomía absoluta de los actores internos con intereses en los procesos internacionales de que se trate.

La situación cambia cuando se trata de cuestiones territoriales o de fronteras vinculadas a la soberanía estatal o la delimitación territorial o marítima, tanto en unos países como en otros, especialmente en aquellos en vía de desarrollo donde el territorio posee una fuerza decisiva en la determinación de la conciencia nacional, la sensibilidad y participación de los actores no estatales es intensa. Es posible establecer un axioma de política internacional según el cual cuando más sensible para la conciencia nacional es un tema de negociación territorial o de delimitación fronteriza, mayor será la participación y la injerencia de los actores internos estatales y de la sociedad civil (legislativo, cortes de justicia, tribunales de garantías constitucionales, gobiernos locales, partidos y movimientos políticos, organizaciones patrióticas, universidades, movimientos regionales, sindicales, etc.).

Las decisiones de la política exterior sobre el territorio y el ejercicio de la soberanía nacional son las que tienen los mayores riesgos de costos internos. Esta realidad, sin embargo, no debe aconsejar el no enfrentarlos porque, en determinadas coyunturas, la política de la no acción puede ser aun más riesgosa. Se trata entonces de abordarlos haciendo una evaluación lo más rigurosa posible.

Abordar la solución de una cuestión territorial requiere en el proceso de decisiones una labor analítica, muy objetiva, dirigida a establecer: 1) los términos de referencia reales del problema; 2) los términos de referencia políticos que tienen que ver con una valoración de las correlaciones de fuerza a nivel interno y externo, en este último caso teniendo en cuenta los factores diplomáticos, militares, económicos y de información; 3) las alianzas existentes y posibles; 4) las características de la situación negociadora; 5) los elementos constitutivos básicos de una estrategia de negociación, en sus aspectos estratégicos y tácticos, que tenga en cuenta necesariamente los factores internos y externos que incidan en ella.

Las negociaciones territoriales o fronterizas, especialmente las vinculadas a la definición de los límites, a su ejecución sobre el terreno o a la atribución de la soberanía territorial o marítima, tienen características propias en relación con su naturaleza, la disposición y la voluntad negociadora, las fases del proceso negociador, el uso de las políticas de poder o fuerza, la utilización de los diferentes componentes del poder nacional y la política de concesiones. Esta especificidad se deriva, en primer lugar, del hecho de referirse a cuestiones que atañen a la soberanía e integridad territorial del Estado y que, por ende, afectan a intereses nacionales primarios. En segundo lugar, porque el margen de gestión de la negociación por parte exclusiva del ejecutivo se reduce por la activación de los controles legislativos de la política exterior y por la emergencia de controles políticos y sociales a nivel de la sociedad civil, al tratarse de una cuestión que afecta a todos los sectores de la nación. En tercer lugar, porque la libertad de los negociadores para adoptar decisiones y realizar concesiones es muy reducida. Y, en cuarto lugar, porque no pueden ser negociaciones con resultados de suma cero -un actor gana el 100\% que pierde el otro- sino de suma relativa, donde las ganancias y pérdidas deben repartirse entre las partes.

Estas características singulares de la negociación de los límites territoriales o marítimos, otras cuestiones territoriales como la demarcación fronteriza, y por supuesto en los casos de la atribución de la soberanía territorial o marítima se expresan desde el punto de vista técnico y 
Revista Peruana de Derecho Internacional

Tomo LXX Mayo-Agosto $2020 \mathcal{N}^{\circ}$ 165, pp. 17-52. ISSN: 2663-0222

Recepción: 30/05/2020 Aceptación: 07/07/2020

político en lo que se puede denominar como las especificidades de las negociaciones relativas a la soberanía nacional.

\section{La especificidad de las negociaciones relativas a la soberanía nacional y a las cuestiones territoriales}

\section{A. La naturaleza sociológica y política de la negociación territorial}

Con relación a la naturaleza sociológica y política de la negociación que supone la capacidad de las partes para llegar a una solución del conflicto, la negociación territorial tiene como especificidad, por la naturaleza del objeto en disputa, la enorme dificultad de las partes de realizar directamente concesiones que resuelvan la confrontación de intereses. Primero porque en la negociación territorial la distribución de pérdidas y ganancias tiende a ser lo que se denomina en la teoría de los juegos de estrategia un "resultado de suma cero o nula", donde todo lo que pierde una parte lo gana la otra, y viceversa. Resultados de esta naturaleza difícilmente son aceptados por una de las partes como producto de la negociación directa, pues la sensación de fracaso o derrota podría ser muy grave para los negociadores y para el gobierno. Y si estas tienen lugar, lo más probable es que existan enormes dificultades para legitimar las negociaciones en el frente interno, incluyendo el procedimiento de aprobación parlamentaria que puede dejar sin efecto la negociación realizada por el ejecutivo. En el caso peruano, existen muchos ejemplos de estas negociaciones en las que no se realizó una evaluación adecuada de la situación negociadora y se pactaron concesiones extremas que finalmente fueron reprobadas por el control parlamentario y la opinión pública. Se citan solo dos ejemplos, uno del siglo pasado y otro del presente siglo:

1) El Tratado García Herrera con el Ecuador, suscrito el 2 de mayo de 1890, a través del cual el Perú se apartó de la lógica del derecho para buscar una transacción política que concedía al Ecuador los territorios de Quijos y Canelos, así como gran parte de Maynas, especialmente en la región del Napo. Extendiendo la soberanía ecuatoriana hasta las riberas del Marañón entre las bocas del Chinchipe y del Pastaza. El congreso peruano determinó que los resultados de esta negociación, llevada a cabo por el ejecutivo, eran naturalmente inaceptables y no aprobó el proyecto de tratado. Al no ser aprobado por el congreso, el texto negociado por el ejecutivo nunca tuvo validez. Pero el congreso fue más allá pues modificó unilateralmente su texto, reintegrando al territorio nacional la parte baja de los ríos Santiago, Morona y Pastaza, dejando así el Marañón bajo la total soberanía del Perú y rectificando de manera similar la línea en la zona del Napo y el Putumayo. Con el texto modificado lo aprobó en 1891. Con esta acción el congreso eliminó toda posibilidad que el ejecutivo pueda renegociar el texto. El congreso ecuatoriano rechazó las modificaciones y en 1894 retiró la aprobación que había otorgado al texto inicial. Todo el proceso volvió a foja cero.

2) La Convención de Lima negociada por el ministro de relaciones de exteriores del Perú, Oscar de la Puente y su homólogo chileno, Enrique Silva Cimma, suscrita el 11 de mayo de 1993. Las negociaciones directas en este caso se efectuaron sin tener en cuenta la naturaleza jurídica, sustantiva y procesal del problema, así como reglas básicas de la negociación. Especialmente la evaluación de la situación negociadora y la identificación de las materias a negociar. Con relación al primer punto, no se evaluó adecuadamente la capacidad de influencia de los actores políticos internos; y, en el segundo caso, parecería ser que no hubo una clara definición jurídica de la naturaleza de los temas pendientes en la aplicación del Tratado de 1929. Por esa razón 
probablemente se consideraron las obligaciones pendientes en torno al muelle y al ferrocarril como un problema de naturaleza jurídica propia del derecho privado, primando un enfoque del derecho de las obligaciones, que desnaturalizaba no solo los intereses peruanos sino que modificaba las disposiciones del propio Tratado de 1929.

Los derechos otorgados a favor del Perú (muelle, ferrocarril y canales del Maure y del Uchusuma) y a los que se refería la expresión obligaciones pendientes, son de derecho internacional público, y su naturaleza jurídica corresponde a la figura de la servidumbre internacional, que conlleva necesariamente una transferencia en favor del Estado peruano de determinadas funciones jurisdiccionales inherentes a la soberanía chilena sobre el territorio de Arica en dichas áreas (Ulloa, 1954).

Una vez que el debate interno en torno a las Convenciones de Lima permitió esclarecer las características de la negociación, y estando las Convenciones en el congreso de la República para su aprobación, el ejecutivo en acertada decisión retiró el pedido de aprobación respectiva, con lo cual no se perfeccionaron. Quedaron sin validez.

\section{B. La disposición y la voluntad negociadora}

La disposición y voluntad de negociar de buena fe como principio básico para el posible éxito de todo proceso negociador, tienen en el caso de las cuestiones territoriales, de límites o de demarcación fronteriza un significado especial con relación a otras negociaciones.

En muchas materias de la negociación, las económicas, comerciales, de propiedad, políticas, diplomáticas, etc. la voluntad de negociación puede ser cierta y consistente, pero también solo un artificio en la medida que un Estado utilice la apertura del proceso negociador como un factor exclusivamente táctico. Sea para ganar tiempo, sea para proyectar una determinada imagen para procesar una situación interna, o para fortalecer su capacidad negociadora en otra negociación simultánea que sí concentre su voluntad política. En otras palabras, muchas veces se utiliza la negociación como un factor diversionista o táctico y, en esas hipótesis, la voluntad de negociar solo es figurada.

Tratándose de negociaciones territoriales que engloban aspectos de soberanía, estas actitudes, corrientes en otras negociaciones, usualmente no se adoptan porque pueden tener costos muy elevados.

En primer lugar, todo proceso de tensión militar o fronterizo siempre conlleva un riesgo de enfrentamiento armado por más localizado que este sea y, en ese contexto, iniciar negociaciones sin la voluntad de llevarlas a cabo puede producir necesariamente el fracaso de estas y acarrear un acrecentamiento de la tensión y del conflicto.

En segundo lugar, iniciado el proceso negociador y establecida la imposibilidad de llegar a acuerdos por falta de voluntad política, la ruptura del proceso siempre tendrá costos políticos y diplomáticos cuyas consecuencias deben analizarse y evaluarse detenidamente, pues normalmente se puede generar crisis político-diplomáticas con efectos internos y externos.

En tercer lugar, cuando se inicia un proceso de negociación territorial siempre entran en juego intereses de terceros países, especialmente de las potencias regionales o globales, y si estas comprometen el desarrollo de la negociación como un objetivo de su propia política exterior, 
puede darse el caso que por las presiones existentes el Estado que inició la negociación sin la voluntad política de concluirla ya no pueda detenerla y pagar los costos de una negociación no debidamente preparada.

Víctor Andrés Belaúnde tenía esa apreciación de las negociaciones peruano-colombianas que culminaron con la cesión territorial de la provincia peruana de Leticia a Colombia. Belaúnde pensaba que Leguía "estaba negociando con Colombia para paralizar cualquier posible intriga chilena durante o después de la Conferencia de Washington, y que su intención era no llegar a ningún acuerdo" (St. John, 1950).

Por regla general, cuando un Estado decide abrir un proceso negociador que implica cuestiones territoriales o de soberanía, para tener control sobre el proceso y defender de la mejor manera sus intereses, debe seguir algunas reglas básicas. No abrir el proceso si no están previamente identificados sus intereses. Tener también muy bien establecidas pretensiones máximas y mínimas. Lo que en teoría de la negociación se conoce como el maximax (posición) y el minimax (elementos). En el rango entre estos dos niveles toda solución en principio será aceptable. Debajo del minimax la negociación ya es onerosa y normalmente el Estado concernido no aceptará una conciliación en ese nivel. Salvo que factores internos o externos así lo determinen.

\section{Las fases del proceso negociador y las políticas de poder, fuerza y concesiones en las negociaciones territoriales}

En lo que concierne a los otros elementos generales de la negociación, es decir las fases del proceso negociador, la utilización de instrumentos de poder y fuerza y los términos de la política de concesiones, las negociaciones territoriales también tienen características singulares.

En torno al proceso negociador, la elaboración del catálogo de cuestiones objeto del litigio o del diferendo debe conllevar una rigurosidad no necesariamente requerida en otro tipo de negociaciones. Cuando se trata de una disputa de territorios o divergencias sobre el trazado de fronteras, el catálogo de posiciones nacionales de cada una de las partes debe ser exhaustivo, con un sustento jurídico sustantivo y procesal lo más elaborado posible. Es muy aconsejable, asimismo, tener el mayor conocimiento e información sobre la posición de la parte contraria y las argumentaciones jurídicas y técnicas dirigidas a demostrar la ausencia de fundamento o racionalidad de dichas posiciones.

Sin embargo, la argumentación dirigida a debilitar o restar sustentación a las posiciones de la contraparte nunca debe llevarse al extremo de desfigurar su naturaleza o sus elementos constitutivos reales. Es determinante para el resultado final de la negociación conocer, a través de información fidedigna y análisis que requieren un gran esfuerzo de objetividad, con la mayor exactitud posible, las reivindicaciones de la otra parte y no confundir lo accesorio con lo principal.

Este discernimiento permite desde la primera fase de la negociación tener una aproximación real sobre las pretensiones de la contraparte que, por lo general, no van a corresponder o se van a alejar considerablemente de las propias posiciones nacionales. Ambas posiciones, por presentar los términos de referencia globales de la negociación, usualmente reflejarán posiciones de máxima y aun más de "carácter negociador", es decir formulaciones que ambas partes ab initio no aceptarían. De allí la importancia de su sustentación, pues cuanto sean más 
creíbles y consistentes, más impacto negociador tendrán. Por estas razones, el primer efecto que se crea con la formulación de las posiciones iniciales será el de un gran distanciamiento entre las partes, inclusive el de la presencia de un aparente o real conflicto irreconciliable de intereses. Sin embargo, como las negociaciones territoriales son de naturaleza jurídica, existen límites razonables para la identificación de las posiciones de máxima. Reivindicaciones extremas sin sustento jurídico pueden ser en ese sentido contraproducentes.

Si las negociaciones son secretas, reservadas o confidenciales, esta exposición de los puntos de máxima pueden ser más flexibles por aplicación del principio de "economía de la negociación", pero si son públicas por presión de los factores internos (opinión pública, partidos políticos, grupos de presión, instituciones nacionales, etc.) tenderán a formularse en el punto de mayor legitimidad interno y de mayor contradicción con la contraparte. La negociación secreta cuando no es conducida adecuadamente puede impedir un eficaz manejo de fuentes y antecedentes políticos y jurídicos, y privar a los negociadores de criterios o conocimientos adicionales. Así, por ejemplo, las evidencias disponibles parecen indicar que en las negociaciones secretas del Tratado de 1922 entre el Perú y Colombia, realizadas por el presidente Augusto B. Leguía y el ministro de Colombia Fabio Lozano, no se utilizaron adecuadamente los antecedentes documentales existentes en el Archivo de Límites, ni el gobierno pudo contrastar las posiciones que manejaba con el sentimiento de la opinión pública nacional (St. John, 1950, p. 239).

La negociación reservada o secreta, al mismo tiempo, presenta bondades insustituibles para tratar conflictos territoriales o nacionales en los que el inicio de las negociaciones o su desarrollo tienen lugar en un ambiente de confrontación extrema que las dificultaría enormemente si se efectuaran públicamente. El caso de las negociaciones palestino-israelíes es una expresión importante de la vigencia de las negociaciones secretas. La naturaleza secreta de las negociaciones se refieren a la no publicidad durante el proceso negociador. Obviamente, al final del proceso, o en cada fase, según cada caso, deben hacerse públicos los resultados.

\section{Las concesiones}

A partir de estas formulaciones de principio, el proceso negociador conlleva un ejercicio de concesiones mutuas que en el caso de las negociaciones territoriales es muy complejo y limitado. Normalmente las partes efectuarán sus concesiones en el contexto de la regla de defender lo principal y conceder en lo accesorio.

Pero si en este punto inicial de transacciones no se consagra el acuerdo, o la correlación de fuerzas bilaterales no produce una concesión "principal" de una u otra de la partes, entonces las probabilidades de bloqueo o crisis de la negociación pueden ser muy altas.

La política de concesiones corresponde finalmente a los órganos de decisión central de los Estados (presidencia de la República, ministerios de relaciones exteriores, consejos nacionales de defensa o de asuntos externos, consejos de ministros), pero los negociadores que proyectan sus instrucciones sobre la mesa de negociaciones juegan un papel central.

Un mal negociador puede no saber generar puntos de transacción favorable, no "leer" bien los términos de la negociación, o no defender adecuadamente los aspectos no negociables de la posición nacional de su país. Un buen negociador puede incluso en determinadas coyunturas realizar acuerdos aparentemente imposibles. Las negociaciones territoriales tienen la 
particularidad de acrecentar las diferencias entre "negociadores duros" y "negociadores blandos" aun al interior de cada delegación nacional. Por ello es muy aconsejable en este tipo de negociaciones que el gobierno central, sin restar a los negociadores la libertad de movimiento que requieren, pueda asegurar de manera sistemática la información y la evaluación pormenorizada de la situación negociadora. Es indispensable asegurar que las instrucciones respondan a la dinámica del proceso negociador, así como para que los aspectos principales de la posición nacional puedan resguardarse más allá de la multiplicidad de fórmulas jurídicas, idiomáticas o situacionales que de hecho emergen en todo proceso negociador intenso.

Las concesiones deben producir resultados de suma no nula, es decir aquellos en que las dos partes resultan ganadoras, probablemente no en la misma proporción, pero donde ninguna pierda el $100 \%$ de los intereses en juego. Si el equilibrio o el relativo equilibrio de las concesiones no es posible de obtenerse en las materias sustantivas de la controversia, muchas veces se buscan concesiones externas, es decir en otras áreas de la relación bilateral o en otros aspectos de la vinculación fronteriza, para encontrar así un punto de equilibrio básico. Es muy rara una negociación territorial o de soberanía con un resultado de suma nula, donde una parte pierde el $100 \%$ y la otra gana el $100 \%$. Las ha habido en la historia, pero son excepcionales. La negociación de los límites del Perú con Colombia, en la que el Perú cedió la provincia de Leticia, es un ejemplo que se acerca a esta hipótesis.

\section{Los instrumentos del poder nacional}

La utilización de los instrumentos del poder en la negociación territorial se diferencia también del resto de negociaciones internacionales por comprender como factores de la negociación todas las posibilidades de ejercicio del poder y la potencia nacional. Entre los principales tenemos a los elementos de poder diplomático inherentes a la negociación como la argumentación y la persuasión, pero estos siempre están vinculados a factores asociados al poder económico, político y al potencial militar e, inclusive, en determinadas coyunturas a la amenaza o al uso de la fuerza. Estos factores de poder inciden normalmente en términos pasivos como un dato de la realidad a tomar en cuenta, pero en cualquier momento de la tensión pueden tornarse activos a través de movilizaciones militares, maniobras, amenazas, exhibición o compra de armamento, etc.

El principal factor de poder pasivo que de alguna manera condiciona la negociación territorial es la correlación de fuerzas militares y político-diplomáticas que, obviamente, pueden no coincidir con la razón jurídica de una u otra de las partes. En 1922 cuando se llegó a un impase crítico en las relaciones entre el Perú y Chile respecto a la convocatoria del plebiscito previsto en el Tratado de 1883 para determinar el destino final de las provincias de Tacna y Arica, la razón jurídica estaba de parte del Perú pero la correlación de fuerzas político-diplomáticas no lo estaba en la misma medida.

A invitación de los Estados Unidos, representantes de ambos países suscribieron en Washington el Protocolo del 20 de julio de 1922 y su Acta Complementaria, a través de los cuales acordaron someter la controversia al arbitraje del presidente de los Estados Unidos.

El Perú sostenía que el plebiscito ya no se podía realizar treinta años después, pues la política de chilenización por la fuerza de las poblaciones de Tacna y Arica había variado totalmente las condiciones originales existentes. Sobre la razón jurídica de esta posición y las perspectivas del 
arbitraje, independientemente si los términos pactados fueron los más favorables o no al interés nacional, Alberto Ulloa ha señalado que el Perú “...ostentaba un derecho de tal manera completo, una situación tan definida y tan limpia, una tesis de un vigor jurídico y de un ambiente moral tan elevados, que estaba justificado al esperar que cualquier árbitro en cualquier momento tenía que serle favorable" (Ulloa, 1977, p.316).

Lamentablemente, la "altura" de los argumentos políticos, jurídicos y morales no son parte de las realidades de las relaciones internacionales como estructuras del poder. Y en ese sentido la posición peruana, en general, y los términos negociados en Washington, en particular, no siguieron principios básicos del realismo en materia de política exterior. El presidente Calvin Coolidge falló en contra de la tesis peruana ordenando la realización del plebiscito. El fallo fue recibido en el Perú con una enorme frustración y un vivo sentimiento nacional de afrontar una injusticia.

Así, Alberto Wagner de Reyna ha escrito en el sentido que "si el Protocolo PorrasAldunate significó una concesión recíproca, el laudo del presidente americano fue un triunfo de Chile; se declaraba posible el plebiscito, se desestimaban los argumentos jurídicos del Perú y las violencias en perjuicio suyo y de sus ciudadanos de Tacna y Arica.

Las condiciones del plebiscito eran también favorables a Chile, pues podían votar los residentes peruanos y chilenos con dos años de permanencia en carácter particular en la zona" (Wagner de Reyna, 1961, p.136). En este caso los "decision makers" peruanos no realizaron una evaluación adecuada de las correlaciones de fuerza, sobreestimando una valoración eminentemente jurídica y subestimando el enfoque político que finalmente es el que explica las realidades de la política internacional, desde las perspectivas del poder. En el caso del Protocolo de Río de Janeiro de 1942, que resolvió el problema de límites con el Ecuador, la situación fue la inversa. La diplomacia peruana utilizó todos los factores del potencial nacional para realizar una negociación de enfoque integral, que permitió con éxito establecer los límites fronterizos entre los dos países.

\section{Tipos de negociación territorial y métodos de solución de controversias}

Otro aspecto del proceso negociador relevante en el caso de las negociaciones territoriales es el de su formato desde la perspectiva de los participantes. Usualmente las partes prefieren negociar directamente entre ellas, o directamente pero con la participación de terceros como amigos componedores o en el ejercicio de sus buenos oficios. Estas opciones tienen una vinculación directa con el método de solución pacífica de controversias que las partes pueden elegir dentro de las distintas alternativas que ofrecen la práctica negociadora y el derecho internacional. Los medios de solución pacífica de controversias comprenden dos grandes métodos: la negociación diplomática y la función jurisdiccional.

Normalmente, como señala el jurista francés Tran Van Minh (Minh, 1980), los Estados históricamente presentan una marcada desconfianza o reticencia a aceptar medios jurisdiccionales. Esto porque dada la importancia de la materia de las disputas, el territorio o el trazado de las fronteras, los Estados -aunque no en todos los casos- prefieren mecanismos de negociación diplomática en lo que tengan una participación directa en el curso de los acontecimientos. En los medios jurisdiccionales, efectivamente, los Estados ponen los asuntos contenciosos al arbitrio de una voluntad ajena cuya decisión se comprometen a aceptar 
obligatoriamente. Y dejar al criterio de un árbitro de un tribunal internacional o de la Corte Internacional de Justicia las diferencias territoriales, renunciando a cualquier participación directa -más allá de la presentación de alegatos o pruebas- no ha sido la norma sino la excepción en las negociaciones de carácter territorial. Largamente se han preferido los medios propios de la negociación diplomática que otorga a los Estados un mayor control de las situaciones y especialmente mayor seguridad, entre ellos las negociaciones directas, las opiniones técnicas, la conciliación y la mediación. Sin embargo, agotados los medios diplomáticos o las negociaciones directas, solo queda la vía jurisdiccional. Por esta razón, tanto la Corte Internacional de Justicia, como los tribunales arbitrales, para ejercer sus competencias jurisdiccionales obligan, en sus estatutos o tratados constitutivos, a que los Estados agoten previamente la posibilidad de llegar a una solución a través de las negociaciones diplomáticas.

\section{Las negociaciones directas o negociaciones diplomáticas}

Las negociaciones directas, ha señalado Maurice Bourquin (Bourquin, 1960), constituyen el procedimiento "más natural y desde cierta perspectiva el mejor. Sin ir tan lejos de decir que un mal arreglo es mejor que un buen proceso jurisdiccional, es necesario reconocer que una solución amigable de la controversia ofrece generalmente ventajas que no se encuentran bajo otros procedimientos".

La expresión de Bourquin es correcta en la medida que, efectivamente, las negociaciones directas son más propicias para el arreglo de las controversias territoriales, pero no porque los Estados prefieran un "mal arreglo" frente a un "buen juicio". En este tipo de negociaciones ningún Estado busca un mal arreglo, todos pugnan por el mejor y más ventajoso arreglo. Y es precisamente por esta razón que se prefiere el trato directo porque es el único que ofrece a los Estados garantías amplias, incluyendo la de no aceptar un acuerdo que lesione sus intereses. Un arreglo por negociación directa puede ser más difícil, más lento, más complejo y demandar mayores esfuerzos nacionales de negociación y acción diplomática, pero al mismo tiempo puede ser el más efectivo y seguro, pues la concertación de dos voluntades libres es la mayor garantía de la permanencia y consistencia del resultado de la negociación.

Esta preeminencia de las negociaciones directas no solo responde a gran parte de la práctica histórica de los arreglos territoriales, de límites o de demarcación fronteriza, sino que han sido privilegiados, asimismo, por el propio derecho internacional, ya que las convenciones y tratados internacionales normalmente otorgan prioridad al trato directo frente a otras alternativas de la solución pacífica de controversias. Son los casos de las cartas de la Organización de Estados Americanos (OEA), de la Organización de la Unidad Africana (OUA) y de las propias Naciones Unidas.

Asimismo, los Estados en sus prácticas diplomáticas vinculadas a las convenciones y tratados bilaterales de límites o fronteras han privilegiado la negociación directa como el principal medio de solución de controversias. Es el caso, en el Asia, por ejemplo del Tratado de Delimitación entre la China y Nepal del 5 de octubre de 1961, o en el África, del Tratado de Cooperación y Amistad entre Nigeria y Túnez (Queneudec, 1961). Ha sido también la práctica corriente en América Latina. Y por excelencia la práctica jurídica mayoritaria de la diplomacia peruana. 
La ejecución de las obligaciones pactadas siguen por regla general fórmulas mixtas, con una primera fase de trato directo y una segunda de dirimencia jurisdiccional. Con la excepción del arbitraje del presidente de la República Argentina en el caso de la frontera con Bolivia y la delimitación marítima con Chile, todos los demás arreglos limítrofes convencionales del Perú con Chile, Colombia, Brasil y Ecuador se han negociado y concluido a través de plurales modalidades del trato directo.

La negociación diplomática como medio de solución pacífica de las controversias de límites está consagrada, asimismo, en las previsiones procesales de algunos tratados de límites.

Es el caso del Protocolo de Paz, Amistad y Límites de Río de Janeiro, suscrito con el Ecuador el 29 de enero de 1942. El artículo VII establece que cualquier duda o desacuerdo que surgiere sobre su ejecución deberá ser resuelto por las partes con el concurso de los representantes de los países garantes. Es claro el establecimiento de la negociación o consulta directa como mecanismo de soluciones de controversias dentro de la estructura jurídica del proceso demarcatorio para llevar al terreno la línea de límites establecida en el Protocolo de Río. El concurso de los garantes debe entenderse como su participación amistosa con base en la solicitud de una o de las dos partes.

La práctica procesal de ejecución del Protocolo así lo ha confirmado durante todo el proceso demarcatorio. Tanto en las campañas demarcadoras del sector oriental como del sector occidental. Las diferencias de opinión o interpretación, dudas o criterios distintos u opuestos respecto del trazo de la línea sobre el terreno se resolvieron siempre en una primera instancia por el trato directo exclusivo, especialmente por parte de los propios presidentes de las comisiones demarcadoras. Solo en el caso de no encontrarse las soluciones a través del trato directo exclusivo se recurrió al trato directo ampliado con el concurso de los países garantes. Este último procedimiento dio origen a los buenos oficios y a la conciliación del canciller Aranha y al peritaje técnico de Diaz de Aguiar, a los que las partes otorgaron el carácter de cosa juzgada tornando sus dictámenes en obligaciones convencionales. Este mismo mecanismo se utilizó para resolver los impases demarcatorios subsistentes, a través de la negociación y suscripción del Acta de Brasilia, el 26 de octubre de 1988.

El Tratado de 1929 con Chile establece una fórmula mixta, las controversias sobre su ejecución son resueltas por las partes a través del trato directo, pero si ello es imposible se establece la instancia decisoria del arbitraje del presidente de los Estados Unidos (Art. 12).

El arreglo directo normalmente puede ser objeto de un tratamiento más amplio, siempre en el ámbito de la negociación diplomática, abierto a la participación de un tercer país o de terceros países que ayudan y cooperan con las partes a través de acciones de buena voluntad que pueden adoptar la forma de buenos oficios, conciliación o incluso mediación.

El trato directo de esta manera presenta dos modalidades, la restrictiva donde solo negocian por lo menos formalmente las partes involucradas, y el trato directo ampliado donde las partes cuentan con la acción conciliadora o mediadora de uno u otros países interesados. La modalidad restrictiva, como ya se señaló, presenta la dificultad que por tratarse de intereses nacionales territoriales difícilmente los Estados de motu proprio están dispuestos a realizar concesiones importantes. Por esta razón, la modalidad ampliada es la más usual y la que ha sido utilizada con mayor frecuencia en la solución de disputas territoriales o fronterizas. Son escasos los casos de solución obtenida a través del trato directo restringido, como el Tratado de 1992 negociado en secreto por el Perú y Colombia. 
El trato directo ampliado ofrece por lo menos tres ventajas adicionales. En primer lugar, la base de sustentación política de la negociación se amplía a otros Estados normalmente de importancia para la relación bilateral de las partes y de igual o mayor dimensión desde la perspectiva del poder político, militar y económico. En segundo lugar, desde el punto de vista de la técnica negociadora, se asocia a la negociación a un tercero o a varios terceros que pueden jugar el papel de limar asperezas, presentar formas alternativas de conciliación, e incluso ejercer presiones para forzar de alguna manera la negociación. Estos elementos de la participación de terceros asociados al trato directo corresponden a las figuras de la conciliación o los buenos oficios. Si se trata de una mediación el asunto ya varía cualitativamente, pues el mediador tiene la facultad otorgada por las partes de presentar fórmulas de entendimiento, de promover su aceptación y de jugar un papel mucho más activo en la negociación.

En no pocos casos los medios diplomáticos están asociados a la participación de un soberano extranjero como árbitro para resolver las controversias, allí donde las partes no hayan podido hacerlo. Las partes convienen, en ese sentido, aceptar el fallo arbitral y normalmente definen de manera previa y muy minuciosa las competencias del árbitro y las materias objeto del arbitraje. Casos históricos son el arreglo de la guerra del Chaco, resuelto el 9 de julio de 1938 por un tratado bilateral y un arbitraje -pactado en el tratado- de Argentina, Brasil, Chile, Perú, Estados Unidos y Uruguay sobre la franja territorial de la frontera extendida desde el río Pilcomayo hasta el río Paraguay; y el arreglo de límites del Perú con Bolivia, resultado de negociaciones diplomáticas entre los dos países y el laudo arbitral de 1909 del presidente de la República Argentina.

Se han dado casos también de arreglos directos con una participación no arbitral sino de discretos buenos oficios y presiones de un mandatario extranjero, como por ejemplo el Acuerdo de Tashkent, del 10 de enero de 1966, que estableció una solución provisional al conflicto fronterizo indio-pakistaní sobre el territorio de Cachemira, el mismo que se pactó con la participación informal y discreta de la entonces Unión de Repúblicas Soviéticas (ONU, 1966).

No es de extrañar que los Estados prefieran el arreglo directo o las soluciones diplomáticas en sus distintas modalidades a las posibilidades ofrecidas por la instancia jurisdiccional. Esto es particularmente notable en el caso de los países de África, Asia y América Latina que han recurrido de manera muy excepcional a la Corte Internacional de Justicia para resolver sus contiendas territoriales, no así las de soberanía marítima.

La base es una desconfianza que se deriva de la sensibilidad nacional y política que presentan los temas territoriales. Por ello, "cuando la integridad territorial está en juego, la desconfianza de los Estados se traduce acumulativamente en reticencia para someter a decisiones obligatorias adoptadas sin su participación por una instancia jurisdiccional que puede otorgar por su decisión un título a la contraparte" (Minh, p.56).

En el caso particular del Perú, la determinación de sus límites territoriales ha excluido la instancia jurisdiccional obligatoria, salvo el arbitraje con Bolivia. Ningún caso ha sido sometido a la Corte Internacional de Justicia. Desde una perspectiva del discurso internacional, ha mantenido con bastante consistencia una posición a favor del arbitraje, aunque su experiencia en el Laudo Coolidge haya sido traumática para la conciencia nacional del momento. 
La soberanía marítima es una materia singular. Muy contemporánea, prácticamente data de la década de los 80, en la que la Convención del Mar atribuyó a los Estados soberanía y jurisdicción hasta las doscientas millas. A partir de esta atribución de la soberanía marítima recién se intensifican las controversias por la delimitación marítima de los Estados cuyas zonas marítimas se superponen. En estos casos el recurrir a la Corte Internacional de Justicia ha sido muy común porque la naturaleza jurídica de las normas de delimitación implican una línea que debe incorporar un resultado equitativo. La equidad infra legen de la norma delimitadora dota a los Estados de una percepción más asequible para resolver este tipo de controversias en el ámbito jurisdiccional.

Un último aspecto relevante de los componentes territoriales y fronterizos de la política exterior de los Estados está relacionado con las dinámicas de cooperación y conflicto que se desarrollan en torno a ellos.

De alguna manera al tratar los medios pacíficos de solución de las controversias territoriales y limítrofes se ha tocado el tema de la dinámica de la cooperación y el conflicto. Los medios pacíficos en realidad abordan las dos dinámicas, pues son providencias cooperativas para solucionar conflictos o tensiones. Sin embargo, es necesario hacer una apreciación específica sobre la cooperación y el conflicto en el ámbito de las cuestiones territoriales y de fronteras.

La dinámica de la cooperación es sustantiva pues comprende, por un lado, la potencialización de las condiciones de desarrollo económico y social de las propias poblaciones de frontera y, por otro, políticas de relacionamiento interfronterizo que en la época actual de la globalización económica tienden a tres objetivos básicos: 1) la libre circulación de bienes, servicios y personas a través de regímenes globales o regímenes específicos de carácter fronterizo; 2) la complementación económica a través de servicios mutuamente utilizados (por ejemplo, la utilización de la energía eléctrica de un país para satisfacer las necesidades de la zona fronteriza del país vecino, el aprovechamiento compartido de las aguas de ríos o lagunas, etc.); 3) la integración de las áreas de fronteras con regímenes comunes de liberalización de bienes, servicios y fronteras (el régimen de la Unión Europea).

Estas modalidades de la cooperación fronteriza puede ser, a su vez, institucional o autogenerada. Es institucional cuando está en el marco de la escena oficial, políticas de Estado a Estado, a través de acuerdos jurídicos o políticos específicos, contando para el efecto con órganos ad hoc como comisiones mixtas, comisiones de vecindad, u órganos de naturaleza binacional. Es autogenerada cuando corresponde a impulsos de las sociedades civiles: comercio, intercambios financieros, tecnológicos, turismo, migraciones, intercambios educativos, deportivos, etc. La integración autogenerada es más real y tiene la particularidad de crear intereses y valores compartidos, desde inversiones hasta mercados locales de bienes y servicios, creando de esta manera intereses materiales contrarios al conflicto o a las tensiones que una vez producidas siempre dañan los intereses de los actores económicos.

Otro elemento sustantivo de la dinámica de la cooperación interfronteriza es de naturaleza política y militar y está referida al fomento de medidas de confianza entre las fuerzas armadas de los países vecinos, especialmente de las tropas acantonadas en sus respectivas áreas de frontera. Existe al respecto una amplia experiencia tanto a nivel mundial como en el ámbito latinoamericano y sudamericano en particular. Las medidas de fomento a la confianza están dirigidas a mantener de manera sistemática la distensión, evitar tensiones o enfrentamientos por 
"accidente", y a resolver incidentes menores a través de códigos de conducta o reglamentos muy específicos.

Es importante tener en cuenta la naturaleza política de las medidas de fomento a la confianza. Están dirigidas a mantener situaciones de statu quo caracterizadas por la distensión; a bajar la tensión cuando esta se haya producido y amenace con alterar el statu quo; a evitar desplazamientos militares u otras actividades que pudieran generar tensión; a establecer sistemas de transparencia y comunicación sobre determinadas actividades o desplazamientos militares; a utilizar mecanismos de diálogo y solución temprana de incidentes en las zonas de frontera, especialmente en situaciones de conflicto donde simultáneamente se desarrollan negociaciones; $y$ finalmente, a administrar de manera eficaz el comportamiento de los efectivos militares en situaciones de normalidad.

Las medidas de fomento a la confianza no constituyen procedimientos de solución de controversias y siempre tienen un carácter instrumental, generan condiciones para no alterar el statu quo o para poder iniciar o desarrollar negociaciones sobre la base del entendimiento mutuo y la buena fe.

El conflicto como categoría de las relaciones internacionales no necesariamente supone la violencia o el uso de la fuerza. Es toda diferenciación de intereses, distensiones en una votación o estrategias alternativas o contradictorias con el manejo de un problema migratorio. Por exclusión abarca todos los ámbitos de la relación internacional en la que prevalecen intereses diferenciados. La amenaza del uso de la fuerza y la guerra son las expresiones más radicales del conflicto. Y la guerra o el enfrentamiento armado, su expresión violenta, definida por el uso de la fuerza. En la dinámica de las relaciones internacionales, cooperación y conflicto siempre se expresan simultáneamente. No hay relación diplomática en tiempos de paz sin la existencia de elementos de diferenciación de intereses, es decir de conflicto de intereses o posiciones. Durante la guerra las negociaciones diplomáticas son parte de ella, pero también la opción para terminarla.

La dinámica del conflicto territorial o fronterizo se caracteriza por tres rasgos específicos: en primer lugar, al tratarse de intereses nacionales vitales, normalmente convoca consensos nacionales, aun en situaciones internas marcadas por una división frontal de las preferencias políticas de la población (el caso del comportamiento de los actores políticos internos y sociales argentinos durante el inicio y la mayor parte del desarrollo de la guerra de Las Malvinas es representativo); en segundo lugar, es el conflicto que más rápidamente compromete la participación de las fuerzas armadas, pues la defensa de la integridad del territorio es por definición su función constitucional; y, en tercer lugar, por constituir una tensión políticomilitar las posibilidades de la escalada del conflicto siempre están presentes, inclusive por la activación de factores de contingencia.

A ello se debe añadir un elemento ideológico, en el más amplio significado de la palabra, como representación de un pensamiento colectivo, en el sentido que los legítimos sentimientos de conciencia nacional, de nacionalismo y patriotismo tienden a concentrarse en las cuestiones territoriales, por ser el espacio el símbolo más manifiesto de la nacionalidad y del patrimonio común de la sociedad. Heredado por generaciones y en torno al cual se han construido gran parte de las historias nacionales y el sacrificio de hombres y multitudes que representan el alto valor de la actitud heroica. 
En ese sentido, la defensa del territorio es no solo una obligación constitucional del Estado en general, y del gobierno y las fuerzas armadas en particular, sino una acción que históricamente ha convocado y convoca la adhesión de la sociedad civil.

Por ello, en todos los Estados existe una suerte de nacionalismo básico vinculado a la defensa y protección de su integridad territorial. De allí que la mayoría de las guerras y los conflictos armados de la historia se han realizado por motivaciones vinculadas al estatuto del espacio nacional, sea para defender territorio, sea para obtener territorio en disputa o sea para expandir los límites globales del territorio, en guerras abiertamente de colonización o conquista.

Tratando de encontrar criterios que permitan sistematizar el conflicto territorial, algunos autores han ensayado clasificaciones que ayudan a una comprensión más analítica de la dinámica del conflicto territorial. Atendiendo a la naturaleza de los conflictos, Jack Child clasifica en conflictos territoriales, conflictos de fronteras, conflictos sobre la posesión de recursos, conflictos ideológicos, conflictos por zonas de influencia y conflictos por migraciones (Child, 1985).

En el ámbito de la variable territorial, es útil diferenciar entre conflictos territoriales y fronterizos. En los primeros se trata de disputas de territorio, es decir de soberanía sobre determinados espacios nacionales; mientras que los segundos se refieren a disputas derivadas de la convivencia de dos soberanías respecto de una frontera delimitada. Los conflictos demarcatorios hacen parte diferenciada de los conflictos territoriales.

Más explicativa es, sin embargo, la clasificación propuesta por Tran Van Minh a partir de las motivaciones o actitudes que impulsan al actor estatal a la defensa territorial, expansión o conquista territorial. Para el fallecido profesor de la Sorbonne, la actitud del Estado respecto a su territorio representa una actitud de pertenencia que si la población lo comparte se convierte en una causa nacional. Por ello, según esa actitud básica de relación de la clase política, del aparato del Estado y de la población respecto al territorio, diferencia los siguientes tipos de nacionalismo territorial (Minh, 1980).

1. Nacionalismo territorial defensivo. Se configura cuando la acción del Estado está dirigida a preservar su territorio, a protegerlo y a defenderlo dentro de sus fronteras usuales o actuales.

2. Nacionalismo territorial irredentista. Se generará cuando un Estado ha perdido una guerra y, como consecuencia de ello, visto cercenado su territorio, suscitándose al interior de este un sentimiento y un movimiento encaminado a recuperar el territorio perdido o reintegrarlo a la soberanía nacional. Como normalmente la anexión de territorios a consecuencia de conflictos armados, especialmente antes de 1945, se formalizó en tratados, el irredentismo territorialista tiende a contestar y demandar la revisión de los tratados. Los Estados que ejercen este irredentismo territorial, que no es otra cosa que un nacionalismo reivindicativo, buscan un argumento jurídico que les permita impugnar los tratados existentes y buscar su revisión.

Un caso típico de esta forma de nacionalismo territorial es la reivindicación boliviana -cuando se basa en la nulidad del Tratado de 1904- por la salida al mar que perdiera a consecuencia de la guerra de Chile contra Bolivia y el Perú, en 1879. Lo es también la reivindicación cubana sobre la base de Guantánamo cedida a los Estados Unidos. 
En este nivel de análisis, es posible diferenciar el irredentismo territorial revanchista del meramente reivindicativo. El primero no es sino una exacerbación del segundo, con dos componentes esenciales, la revancha militar y el culto a las provincias perdidas. El caso más típico de la historia europea ha sido el de Alsacia y Lorena, que galvanizó a la nación francesa en la búsqueda de una obsesión nacional: la recuperación de las provincias perdidas y la derrota militar de Alemania. El 1 de marzo de 1887, Víctor Hugo en la asamblea nacional francesa, señaló elocuentemente: "Quién ha permitido a Alemania que encuentre la felicidad y sentirse fuerte con dos provincias de más y la libertad de menos. Nosotros !...Oh! llegará la hora de la revancha prodigiosa ...sí desde mañana, Francia no tendrá sino un solo pensamiento: ... recuperar fuerzas, erguir a sus niños, alimentar con las santas cóleras a esos pequeños que devendrán adultos, forjar los cañones y formar a los ciudadanos, crear un ejército que sea el pueblo entero, llamar a la ciencia en auxilio de la guerra, estudiar las tácticas prusianas como Roma estudió las tácticas púnicas... Y después, todo de un golpe, un día él encontrará la dirección correcta: veremos renacer de un bond la Lorraina, renacer la Alsacia!..." (Hugo, 1964, p. 694-695).

En la historia de los conflictos territoriales del Perú no ha existido como política del Estado un irredentismo territorial revanchista, aunque sí en el pensamiento de determinadas personalidades o sectores importantes de la población, especialmente en la fase inmediata a la posguerra con Chile y eminentemente en Manuel Gonzáles Prada, para quien Tarapacá, Tacna y Arica fueron efectivamente la Alsacia y la Lorena del Perú, y cuyo verbo y dignidad frente a la derrota y la ocupación no fue menos elocuente que la de Víctor Hugo: "Cuando tengamos pueblo sin espíritu de servidumbre, y militares y políticos a la altura del siglo, recuperaremos Tacna $\quad$ y Arica, entonces y solo entonces marcharemos sobre Iquique y Tarapacá... Hoy que Tacna rompe su silencio y nos envía el recuerdo del hermano cautivo al hermano libre, elevemos unas cuantas pulgadas sobre el fango de las ambiciones personales, y a las palabras de amor y esperanza, respondamos con palabras de aliento y fraternidad" (Gonzales Prada, 1960).

Más allá de los sentimientos y el verbo de Gonzáles Prada y de su posición digna sobre la guerra con Chile, el caso de Tacna y Arica más bien se ubica en la historia peruana dentro del irredentismo territorial reivindicativo. La propia acción diplomática peruana y el comportamiento de la sociedad civil durante cerca de medio siglo, desde 1883 hasta la la partición adoptada por el Protocolo de 1929, junto a la fundamentación jurídica de derechos, impulsó y se sustentó en los más sanos y elogiables sentimientos de pertenencia nacional, de dignidad individual y colectiva y de amor nacional. Muy especialmente en los pueblos de Tacna y Arica que tuvieron que enfrentar las condiciones de fuerza más adversas para defender su derecho humano a la nacionalidad y su filiación por el Perú.

El tercer tipo de nacionalismo territorial es el expansionista. Y si bien es cierto que se concreta de manera peculiar con el surgimiento de los Estados naciones, ha existido desde el surgimiento de las primeras sociedades políticas. Independientemente de las razones económicas que pueden existir para explicar la historia del expansionismo territorial o la guerra de conquista, Tran Van Minh aporta una etiología fundada más en razones políticas y culturales. Así diferencia el expansionismo místico y el mito del destino nacional del expansionismo nostálgico y la teoría de los derechos históricos (Minh, 1980).

El expansionismo místico y la teoría del destino nacional han conocido una evolución a partir de la segunda posguerra mundial con relación a sus manifestaciones pasadas. Hasta antes de 
esa fecha, siempre se expresó en una forma primitiva que combinaba poder, argumentos simplistas y métodos brutales.

A inicios del siglo XX surgió la teoría del espacio vital y sus derivaciones geopolíticas que explican el expansionismo pregonado por el régimen fascista de Benito Mussolini. No lejos de estas ideas simplistas de resolver los problemas de natalidad y crecimiento de la población por la búsqueda del espacio vital en soberanías ajenas, estuvo también el militarismo japonés de 1919 a 1939. La mayor expresión de este nacionalismo expansionista primitivo fue la ideología nacional socialista de Hitler que se aplicó de manera descarnada y brutal a partir de 1941. La segunda guerra mundial se inició en la fanática búsqueda de Hitler de un espacio vital nuevo para Alemania con relación a la cifra de su población, fue la búsqueda fanatizada de un "libensraum" más allá de sus fronteras históricas.

La forma moderna del expansionismo místico ha sido vinculada en el contexto de la guerra fría a acciones mucho más sofisticadas que no buscaban directamente el control de territorios, sino de las poblaciones a través de valores universales antinómicos como el "mundo libre" y la "comunidad socialista". En la actualidad, con los cambios operados en el sistema internacional, esta categoría de análisis ha perdido funcionalidad y ya no tiene vigencia.

Finalmente, tenemos el caso singular de un tipo de nacionalismo territorial expansivo sui generis que es el denominado "nostálgico" vinculado a la teoría de los derechos históricos. Según Tran Van Minh, algunos Estados en desarrollo, pequeños por lo general, "ensayan encontrar en el pasado fundamentos para sus pretensiones anexionistas recurriendo entre otros al argumento de los derechos históricos. Este caso de expansionismo, al no encontrar sustento de posesión ni título jurídico sobre los territorios pretendidos, recurre a los derechos históricos, doctrina no consagrada por el derecho internacional, y al obsoleto derecho del descubrimiento.

En realidad, se trata de representaciones ideológicas del espacio para afirmar un sentimiento nacional. Es el caso, por ejemplo, de las reivindicaciones de Marruecos sobre Mauritania en 1960; y en América Latina, la tesis que el Ecuador sostuvo desde mediados del siglo pasado hasta 1942 con relación a Tumbes, Jaén y Maynas, territorios que simplemente no formaron parte de su constitución inicial como Estado y respecto de los cuales nunca ha tenido ni posesión ni títulos.

Independientemente que los Estados actúan bajo cualquiera de las motivaciones del nacionalismo territorial, lo cierto es que la relación Estado - nación territorio continúa siendo fuente de tensiones fronterizas, de conflictos y guerras a través de procesos que se expresan con autonomía de las tendencias globales del mundo contemporáneo.

En ese contexto, el Perú es uno de los países latinoamericanos -por su historia y geografía- que está obligado por las "fuerzas profundas", en el lenguaje de Maurice Duverger, a otorgar una prioridad esencial a las variables territoriales, especialmente en las áreas de la defensa nacional y el desarrollo y la integración fronteriza. Se trata de armonizar los requerimientos de relaciones fronterizas cooperativas con una una política de defensa nacional que las contenga y promueva, pero que ejerza, al mismo tiempo, la capacidad disuasiva necesaria para asegurar la paz.

El fallo de La Haya sobre el límite marítimo con Chile ha creado una situación nueva en la que la dinámica de la cooperación y el conflicto debe prevalecer en todas las fronteras. Se abren posibilidades reales que por primera vez en la historia la paz pueda reposar no solo en la 
Revista Peruana de Derecho Internacional

Tomo LXX Mayo-Agosto $2020 \mathcal{N}^{\circ} 165$, pp. 17-52. ISSN: 2663-0222

Recepción: 30/05/2020 Aceptación: 07/07/2020

inexistencia de controversias de límites en las cinco fronteras, sino en proyectos de integración fronteriza donde el protagonismo de las relaciones bilaterales pase a las poblaciones civiles y a las dinámicas de la integración fronteriza, económica, física, social y cultural.

\section{Notas}

1. Friedrich Kratochwil, Peace and disputed sovereignty: Reflexions on Conflict Over Territory. Columbia University, Institute of War and Peace, University Press of America. New York, 1985.

2. Marcel Merle, La politique étrangère, Presses Universitaires de France, Paris, 1984.

3. Alberto Ulloa, Derecho Internacional Público, 1950.

4. Alberto Ulloa, La posición Internacional del Perú, Editorial Atlántida, S.A., Lima, 1977.

5. St. John, Bruce, Peruvian Foreign Policy, 1919-1939: The Delimitation of Frontiers. Ann Arbor, MI: University Microfilms, Inc., 1970.

6. Alberto Wagner de Reyna, Los Límites del Perú, Editorial universitaria, Lima, 1961.

7. Tran Van Minh, Le nationalisme territorial, en; Actualité de la Question Nationale, PUF, París, 1980.

8. Maurice Bouquin, Mélanges Basdevant, Ed. Pedone, París, 1960.

9. J. P. Queneudec, "Le règlement des conflits frontaliers en Afrique", en : Revue générale de droit international public, 1961, Paris, p. 377 y s. Asimismo, M. Bedjaoui, "Le règlement pacifique des différends africains", Annuaire français de droit international, París, 1972.

10. Crónica mensual de la ONU, N.Y., vol. III, N. 4, abril de 1966, pp. 42 - 43.

11. Jack Child, Geopolitics and Conflict in South América, Quarrels Among Neighbors, tosd. Praeger, N.Y., 1985.

12. Víctor Hugo, Oeuvres politiques complètes, J.J. Pauvert, éditeur, París, 1964, pp. 694 - 695.

13. Manuel Gonzáles Prada, Discurso en el Politeama, en Páginas Libres, Ediciones Páginas Libres, Lima, 1960. 